\title{
Compulsory Commitment to Care of Substance Misusers - A Worldwide Comparative Analysis of the Legislation
}

\author{
Magnus Israelsson* and Arne Gerdner
}

\author{
Department of Social Work, Mid Sweden University, SE-831 25 Östersund, Sweden
}

\begin{abstract}
This study explores the worldwide use of compulsory commitment to care (CCC) at the end of the $20^{\text {th }}$ century and evaluates the implementation of WHO recommendations since the 1960s. Based on three WHO reports, the legislation of 90 countries and territories are analyzed, and types as well as predictors of such legislation are analyzed in multivariate models from country characteristics. Laws on CCC for alcohol and drug misusers are common all over the world; more than 80 percent of the countries and territories studied have such laws. The majority use civil commitment acute or rehabilitative - in accordance with welfare logic, while a large minority still uses commitment under criminal law, based on a moral logic. Civil CCC is positively related to strong economies or having been part of the Soviet legal system. CCC under criminal law is negatively related to the same factors.
\end{abstract}

Keywords: Alcohol, drugs, substance misuse, compulsory commitment to care, mandated care, coercive care, involuntary care, comparative analysis, legal, international.

\section{INTRODUCTION}

Durkheim claimed that when societies develop from simple to more complex, their sanctions against social deviations change from repression to restitution, i.e. from punishment and social exclusion to restoration of the individual's human dignity through social integration and rehabilitation [1]. Post-modernism criticized the very idea of a linear historical development [2], an idea that can be traced behind Durkheim's claim. That idea has been illustrated by examples. Many diseases previously viewed as moral deviations are now accepted, for example such well-known older plagues as leprosy and tuberculoses, as well as the modern plague HIV-AIDS. Suffering people were stigmatized when people viewed their diseases as more or less regarded as a punishment from God, or resulting from an unclean or sinful life. Conrad described that some emotional and behavioural disorders seem to have wandered the same path, including depression, hyperactivity, obesity, learning problems and alcohol and drug dependence [3]. If so, these processes seem sometimes to be long and windy and to include setbacks as well as progressions, sometimes parallel but often divergent between various countries [4]. Black [5], seemingly building on Durkheim, claims that law as governmental social control is a quantitative variable that tends to grow, but also that it varies in how to treat deviant human patterns. He describes several styles of law, penal, compensatory, therapeutic and conciliatory, each corresponding to various types of social control. This study concerns the variation between countries in how to treat alcoholism and addiction, especially focusing on the penal and therapeutic types of governmental social control, i.e. legislation.

*Address correspondence to this author at the Department of Social Work, Mid Sweden University, SE-831 25 Östersund, Sweden;Tel: +46 (0) 6316 57 83; Fax: +46 (0) 63165588 ;

E-mail: magnus.israelsson@miun.se
Alcoholism was described as a disease in medical and social research by Benjamin Rush and Thomas Trotter in the eighteenth century and by Magnus Huss and Carl von BrühlCramer in the early nineteenth century [6-8]. Yet official and international recognition of the alcohol and drug dependence syndromes as diseases waited until 1976, with the inclusion in the ninth version of International Classification of Diseases and Causes of Death (ICD-9) [9]. Although the official recognition is important, it is only a milestone in an ongoing process, in which both moral and health-oriented perspectives may exist in a society at the same time, and even result in hybrid phenomena, mixtures between the two [10]. Such processes may include many factors and may therefore be non-linear and perhaps differ between parts of the world.

Some possibly relevant factors for this process during the last century can briefly be noted. In many western countries in the $19^{\text {th }}$ century, excessive drinking habits were acknowledged as a severe problem that affected large parts of the population. Popular resistance organized in the temperance movements that developed in North America as well as in Europe to combat what was regarded as a threat to health and welfare. These popular movements were often guided by moral pathos and reform-oriented progressive ideology and were affiliated with the labour movement as well as with Christian revivalist churches [4]. Although prohibition of liquor was the demand in many countries, in fact only a few - like Finland and the USA - implemented this. Instead of - or in combination with - controlling the flow of alcohol, many countries in the western world during the first decades of the century enacted laws on compulsory incarceration to control the alcoholics [11-15]. The word "asylum" was used, parallel to the mental asylums. It implied that the important factor was to let the alcoholic rest from the turmoil of the habit. Sometimes these laws referred to the incarceration as "care", but in most cases such care was carried out in large institutions with forced labour as the 
main or only content $[14,15]$. Similar systems developed in the countries of Eastern Europe, under communist rule [16], and when countries in East Asia faced drug epidemics after World War II, such as the amphetamine epidemic in Japan, the opium epidemic in China and the heroin epidemic in Singapore, they were based on popular moral campaigns and entailed compulsory incarceration of addicts in forced labour camps and harsh penalties for dealers [17, 18]. Japan at that time was under authoritarian role; in China the program was part of the political campaign launched by the new communist regime; in Singapore it was implemented by a democratically elected government with strong popular support.

In the absence of clear treatment content, the "asylums" in Europe developed as large institutions with more emphasis on control than on rehabilitation, as described by Goffman [19]. Criticism of such institutions focused both on the issue of infringements of civil rights and the lack of a treatment content [20]. These institutions were seen as repressive and mostly directed towards the underprivileged $[12,13]$. Subsequent demands for rehabilitative milieus and treatment content inspired both the development of therapeutic communities and the creation of outpatient treatment and community care models [14]. Although there were examples of introducing rehabilitation and care also within the asylums, ideological controversies appeared among social workers and addiction treatment professionals whether or not compulsory commitment should have any place in the treatment system [12]; but, when the HIVepidemic spread among addicts in western countries in the 1980 s, means of control were again called for and strong emphasis on compulsory care of various types reappeared on the agenda [12]. Wang describes how compulsory care models were re-established in China during the 1980s after the opening of the country to foreign influences in 1979, which provoked a new epidemic wave of opiate misuse [21]. On the other hand, when the Soviet Union was dismantled in the 1990s, many of the old compulsory care models - with the same focus on work and adjustment rather than on treatment - were abandoned following demands for more respect for civil rights. Such criticism was also fuelled by new inspiring research, based on meta-analyses concerning the effects of pharmacological as well as psychosocial treatment of alcoholism and drug addiction, which seemed to support a new optimism that effective rehabilitation would make mandated care unnecessary ${ }^{1}$. However, due to a severe opiate epidemic, the Russian authorities are again planning to rely more on compulsory commitment [23].

From these short glimpses of the CCC history, one may get the impression that alcohol or drug related epidemics seem to fuel demands for compulsory care legislation that is then abolished or softened during more libertarian periods, but again called for in times of new epidemic outbreaks. However, other factors may be just as or more important for this process, such as demographics, or welfare ambitions and the resources of the society to implement them. Treatment if professional - is expensive and alcoholics or addicts who do not request and sometimes reject treatment is less likely to get priority when a society is short of resources and has to

${ }^{1}$ From AG's discussions with representatives for the Russian Ministry of Health in 2001. feed a large population outside the labour force, e.g. with large populations under-aged, or retired, or disabled. Even in a fairly rich country like Sweden, the economic crises during the 1990s struck hard against the treatment of alcoholics and drug addicts, including compulsory care [22].

Additionally, ideologies seem to be important. Compulsory care has been criticized under banners of civil rights. History and culture may also play a role. Obviously the Muslim or Sikh bans on alcohol drinking are relevant factors both for the epidemiology of alcoholism and for the legislative bodies concerned with how to cope with it. Domination by a stronger country, e.g. a colonial power, may also have strong impact on legislation.

Thus, the process described by Durkheim and others is complex, varying over time and in different parts of the world. This study is not, however, concerned with the process as such. Instead it is intended to assess the situation concerning compulsory commitment to care for adult substance misusers as this is reflected in national legislation at the end of the $20^{\text {th }}$ century. Here, we will review the situation in different countries in all parts of the world and empirically explore the relevance of various country factors for such legislation.

The focus of this article, thus, is on the worldwide variation in national legislation concerning compulsory commitment to care and the country factors related to this variation. Based on three WHO-reports, the legislation of 90 countries and territories is analyzed, and types as well as predictors of such legislation are explored from country characteristics.

\section{COMPULSORY COMMITMENT - VARIOUS TYPES AND RATIONALES}

Compulsory commitment to care for adult substance misusers (CCC in the following) has for many years been a controversial option when voluntary care for any reason is ruled out. According to the principle of self-determination people should have the right to make their own decisions concerning different aspects of their own lives, but there is also a generally accepted duty to try to minimize personal harm (the harm minimization principle), especially to those who are most vulnerable. In case of addiction, these two ethical principles are often in conflict [24-26].

Here we must distinguish CCC from other types of coercive care. Personal distress, physical symptoms and social pressure from family or employer may all be experienced as coercive pressure to force misusers to accept treatment or rehabilitation. In such cases, the alternative to treatment is to risk the negative consequences of a refusal, e.g. divorce, losing one's employment or undesired health effects. Misusers who are also criminal offenders may experience pressure from the legal system to accept treatment or care instead of having to serve time in prison. Here too, the misusers have the option to refuse care, but must then take the negative consequences of their decisions. These are various examples of coercive care, but they are not CCC. Crucial is that those persons still have choices even if they may dislike the restricted options offered. CCC means that misusers are not given any legal choice to avoid and/or to leave care or treatment, i.e. they are by law mandated to care or treatment [12]. According to Weisner, coercive 
measures can be seen as a continuum depending on the degree of external pressure vs personal options [15]. On such a continuum, CCC would form the "severe end" since external pressure totally outranges personal options. In most countries this type of intervention is reserved for the severest cases of alcohol or drug misusers. Laws in this area are, as described by Porter et al. [27, 28], either organized under criminal law, mental health legislation or social (or special) legislation. CCC under criminal law implies that a person is sentenced to treatment due to an offence. This offence may be 1) when use, misuse or possession for own use in itself is criminalized, 2) due to other crimes related to use or misuse, e.g. dealing drugs, theft in order to finance use, driving or committing other crimes under the influence, or 3) due to other crimes committed by an addict but not necessarily related to his or her misuse.

There are two other types of compulsory commitment that are both referred to as "civil commitment" [15]. Mental health laws are designed for patients based on their need for psychiatric care, where compulsory commitment is an option only for persons who by the medical profession are found to be incapable of assessing their own need for care. Such laws are often consistent with the Hawaii and Madrid Declarations of the World Psychiatric Association (WPA) $[29,30]$. In this situation, it is held that there is less conflict between the right to self-determination and the demand for harm minimization since the persons cannot execute their right to self-determination. In many countries, such incapability is only stated when the persons suffer from severe cognitive or affective disorders, e.g. dementia, psychosis or severe depression that may or may not be related to prior or ongoing misuse [12]. Some countries, however, may include "addiction" or "substance dependence" among disorders that in severe cases may cause incapability to make decisions concerning own need for care [31]. The Hawaii Declaration accepts compulsory treatment only when the patients are incapacitated, while the later Madrid Declaration also includes those "unable to exercise proper judgement because of a mental disorder" (own italics). It further states "No treatment should be provided against the patient's will, unless withholding treatment would endanger the life of the patient and/or those who surround him or her" [29, 30]. Thus, for compulsory commitment to psychiatric care, 'presumed coercion' (see below) is the common ground, while the need-for-care and danger criteria are additional prerequisites. Both of these can be derived from the harm minimization principle, but while the need-for-care criterion focuses only on the individuals' health problems (resulting in danger to themselves), the danger criterion also includes danger to others due to lack of personal control under the influence of alcohol or drugs resulting in violent or other dangerous behaviour. Danger to others should according to WPA be restricted to "those who surround him or her". This is, however, not always clear in national laws, which sometimes simply state "others" and sometimes go so far as to include the broader danger of harm to society, e.g. in the US Narcotic Rehabilitation Act, which refers to when acts "endanger the public morals, health, safety..." [32].

Based on comparative studies of social policy and law in some industrialized countries, Tännsjö has presented a useful categorization of the different ethical grounds for coercive measures applied within health care and social service systems [33]. Measures in the interest of persons who lack decision capacity is based on the presumption that the person would accept the decision if he/she had that capacity and are therefore characterized as presumed coercion. Coercive measures taken in the interest of a person who may have some capability for making own decisions but regardless of his/her own expressed will are characterized as paternalistic coercion. Measures taken to prevent harm to others are characterized as preventive coercion. In addition to these three, Tännsjö mentions a type of coercion based on the will of the individual expressed prior to the situation. This is called Homeric or Ulyssian coercion, since it is described by Homer in his writings on Ulysses, who asked to be tied up and decided that no-one should pay any attention to his demands to be set free, when he heard the calling songs of the Sirens. Here, this would imply that an addict gives consent at an initial stage to be held against his or her will later, if he/she wants to leave treatment prematurely. All of the above occurs in various national and state laws. In addition, there is so-called penal coercion i.e. compulsory commitment against offenders, since criminal law may or may not give reference to any other ethical criteria.

Paradoxically, two types of coercion, at least in theory, give priority to the individual's own will, which is either expressed (Homeric) or presumed. These two differ, however, in their assumptions concerning the committed persons' decision capability. While presumed coercion assumes that the person has problem with accepting necessary help initially, Homeric coercion assumes that the person has problems later on with maintaining his or her initial decision. The other two types of civil commitment paternalistic or preventive - do not build on any specific assumptions concerning decision capacity. Nevertheless, according to a comparative study by Segal, there are important differences between them with regard to who is targeted [34]. "Danger to self or others" tends to target young out-acting male addicts more than women or older persons suffering from severe health problems, while paternalistic coercion is meant to target addicts with more psychiatric or somatic health problems, who more often are older and more often women. Obviously, penal coercion targets offenders only.

\section{INTERNATIONAL RECOMMENDATIONS AND REPORTS}

Since the 1960s, The World Health Organization (WHO) has monitored the efforts of its member-states to control the use or misuse of alcohol and other drugs, and has presented several reports. The first international survey of national legislation concluded that legislation designs in the countries examined differed widely [35]. In many countries, legislation had a penal direction and bestowed punishments of various severities on misusers. In other countries, misuse and addiction were not seen as moral but rather as health problems. WHO reported a growing international tendency to understand misusers as sick and in need for adequate care. In 1967, ten years before the inclusion of substance misuse disorders in ICD-9, the WHO Expert Committee on Mental Health recommended that legislations concerning persons dependent on alcohol and/or drugs should recognize these as persons as sick; that medical and health experts should be 
involved in the framing of such legislation; that adequate treatment and rehabilitation should, if necessary, be ensured by civil commitment to medical authorities for supervision and care from initial diagnosis to rehabilitation, and that services to these persons should, as far as possible, be integrated with other health and welfare services [36]. WHO recommends voluntary treatment as preferable, but also states that compulsory treatment of persons dependent on alcohol or other drugs often is successful; stressing, however, that civil commitment should be preventive and therapeutic in its aim and that ample services must be available [36].

The second international WHO survey on national legislation from 1986 comprised detailed information on legislation in 42 countries and one territory and noted that the differences concerning the type of legislation used to regulate mandatory care and treatment still remained [27]. The survey caused WHO to publish, in the following year, a practical guide for the improvement of national legislation on treatment programs [37]. In 1990, the UN General Assembly adopted a resolution to confirm WHO's supportive function in assisting the member states to develop or adapt national legislation in this area [38]. In its 29th report the WHO Expert Committee on Drug Dependence stated that WHO should develop a full range of costeffective treatment and rehabilitation programs and also initiate the development of guidelines for the treatment and rehabilitation of drug-dependent persons as a form of assistance to national health authorities [39]. The 30th WHO Expert Committee on Drug Dependence provided further recommendations and gave certain notice to the widespread use of mandatory measures in the care and treatment of substance misusers and to the advocacy for even wider use [40]. WHO recommended analysis of the ethical issues raised by such treatment, and of the advantages and disadvantages of the different forms it takes.

In 1999, the third WHO international survey of national legislation was presented to follow-up legislative developments in member states [28]. The survey compiled information on the legislation of 77 countries and territories and found that there were still large differences in the type of legislation that the countries preferred to use to regulate mandatory and voluntary care/treatment. This report, like the 1962 survey, showed that many countries still have legislation with a penal direction, while others have adapted their legislation in accordance with WHO recommendations.

Since the collapse of the Soviet Union resulted in a number of new UN member-states, an additional report presented a legislative survey on primarily Eastern Europe and the newly independent states [41]. This report also includes contributions presented in a conference arranged by WHO Europe together with the European Council in Moscow 1999, as well as a consensus statement adopted there. The conference was intended to support the legislative work in progress in many of these countries. In its recommendations, it was stated that drug or alcohol dependence causes considerable harm both to the addicted person and to the environment, which in some cases might warrant coercion into treatment. Those eligible for compulsory treatment are persons with alcohol or drug dependence who pose serious threat to health and well-being of themselves and significant others. The ultimate goals of compulsory treatment are the rehabilitation of the dependent person and the protection of society and such treatment is justified only when governed by the same principles that apply to the overall health system: human dignity, equity, solidarity, targeted on health, focused on quality [41]. Since 1960 s, thus, and still, the WHO recommendation is to handle substance misusers as sick individuals who should be provided with care and treatment within the health and welfare system of each member country. Despite noticing that there are ethical problems involved, CCC is seen as an option when needed voluntary care can not be provided. It has been recommended that $\mathrm{CCC}$ in criminal law preferably should be replaced with civil commitment.

\section{AIM OF THE STUDY}

The study investigates to what extent the WHO recommendations have been transferred into national legislation and what country factors are related to such transfer. Based on the presentations of national legislation, variations of $\mathrm{CCC}$ at the end of the $20^{\text {th }}$ century are studied, including such descriptors as type of law, maximum length a person can be held and ethical rationale. Additionally, the study explores whether the choice of law can be explained by variation in country specifics. Can they be understood from differences in the amount of substance misuse problems or in the resources to handle such problems? Are they symptoms of variations in the political systems or in the civil liberties of citizens? Do they emerge due to variations in demographic prerequisites or differences in the general welfare? Do they reflect cultural situation or historical past, e.g. religion and former colonial status? These variations and possible relations can be explored in quantitative comparative analyses using regular statistical methods [4244].

The aim of this article is to evaluate the national applications of the WHO recommendations concerning CCC by exploratory comparative analysis covering the legislation of 90 countries (or territories) on all populated continents. It gives a general description of the variation of laws on CCC, including length in care/treatment, type of legislation and ethical rationale. Occurrence and type of $\mathrm{CCC}$ are analyzed in relation to demographics, the amount of the problems, resources, political and cultural factors and general legal system. The study only concerns the laws as such, however, and does not explore the implementation of these laws, neither in terms of the number of compulsorily committed persons, nor how the actual institutional care or treatment under these laws is organized and delivered. ${ }^{2}$ Neither are outcomes or effects of compulsory care studied here. The study concerns only CCC of adults who are alcohol and/or drug misusers. Legislation concerning children and adolescents, and compulsory commitment for other psychiatric problems is not investigated. ${ }^{3}$

\footnotetext{
${ }^{2}$ Such data were not available or easily accessible for more than very few countries. However, future studies are planned to provide this on a European level.

${ }^{3}$ In a few countries laws on CCC may concern both adults and adolescents. They are, however, included here only concerning aspects that apply to adults.
} 


\section{MATERIAL AND METHOD}

The selection of countries derives from three WHO reports [27, 28, 41]. Selection criteria mentioned in the first report was "to include countries of varying social, cultural and economic characteristics, legislative systems, pattern of health services, economic development and population size" [27, p. 10]. A similar approach was used in the second report while expanding this to include more countries. All populated continents are represented about equally well, with the exception of countries of West Africa due to lack of data. In the case of China, the official administrative system "one country, two systems" means that Macau and Hong Kong are handled here as separate territories. On countries with a federal structure, both federal and state laws (if available) are included, and the country is reported as a country with CCC legislation even if the law is functional only at state level. ${ }^{4}$

Porter et al. (1986) have considered legislation enacted up to September 1982 and contribute to this study with data for three countries [27]. Porter et al. (1999) considered legislation enacted up to November 1999 and provide this study with data for 73 countries [28]. The WHO survey of 2001 considered legislation active in 1999 and supplies data for 14 countries [41]. All laws were referred to as active in the respective reports. Many countries may since then have made amendments to their laws or enacted new laws in this area. The material however reflects the situation worldwide at the end of the $20^{\text {th }}$ century.

Both the 1986 and 1999 surveys were based on legislative information from the following sources: a) complete texts of legislation and summaries of texts published in the International Digest of Health Legislation, b) complete texts of legislation published by the United Nations Division of Narcotic Drugs (E/NL series), c) United Nations and national government legislative documents repositories. For the 1986 survey, WHO also gathered information through personal communication with professionals in the surveyed countries. For the 1999 survey, WHO addressed questionnaires to respondents in the countries surveyed and also obtained personal communications from these respondents. The 2001 report is not like the previous two a worldwide survey but a report from a meeting arranged by WHO Regional Office for Europe (WHO/ EURO) and the Council of Europe in collaboration with the Ministry of Health of the Russian Federation at request from several newly independent states (NIS) of the former East Bloc. The purpose of the meeting was to increase the knowledge and capacity of East European countries, and particularly the NIS, to develop adequate policies regarding non-voluntary treatment of alcohol and substance abuse. The report also presents a survey of active CCC legislation in 16 European or Asian (NIS) countries. WHO/EURO was

${ }^{4}$ Of the 16 federal countries, one country (Pakistan) had no CCC, while 14 countries had federal law of some type on CCC. For the remaining federal country (Canada), WHO [28] reported CCC only on state level with examples from two states, but according to a ministerial press release, CCC laws exist in seven states [61]. Six other countries had CCC laws on state level in addition to federal law. For the US, we could also compare with Leukefeld \& Tims [45], who reported on 49 of the US states. In 42 of these the state had its own CCC institutions for alcoholics and/or drug addicts. Although not a federal country, mainland China is a very large country with great diversity between regions. Wang [21] reports, however, that CCC institutions exist in all regions. responsible for this survey, conducted through questionnaires to key contacts in the 16 countries. When countries appeared in more than one report, we chose the two more recent ones and among them the one with the most legible and comprehensive information on that specific country.

The 90 countries and territories analyzed in this study represent great variations in social, cultural and economic characteristics, legislative systems, development of national policies and patterns of health care services, economic development and population size, and are sufficient for the quantitative comparative approach in this study, i.e. to analyze the variations and relations of legislation in different countries globally.

\section{Explored countries (with territories within brackets) are:}

Africa: Egypt, Kenya, Madagascar*, Mauritius, Nigeria, Senegal, Seychelles, Somalia*, South Africa, Tunisia, Zambia* and Zimbabwe

Asia: Afghanistan, Bahrain, Bangladesh, China, (Hong Kong), India, Indonesia, Iraq, Iran, Israel, Japan, Jordan, Kazakhstan, Kuwait, Kyrgyzstan†, (Macao), Malaysia, Myanmar, Pakistan, Philippines, Qatar, Singapore, Sri Lanka, Tajikistan $\uparrow$, Thailand, Turkey, United Arab Emirates, Uzbekistan $\dagger$ and Vietnam

Europe: Armenia†, Austria, Azerbaijan†, Belarus $\dagger$, Cyprus, Czech Republic†, Denmark, Finland†, France, Germany, Georgia†, Great Britain, Greece, Hungary, Ireland, Italy, Latvia, Lithuania $\uparrow$, Malta, Moldova $\uparrow$, Norway, Poland $\uparrow$, Portugal, Russia $\uparrow$, San Marino, Slovakia, Spain $\dagger$, Sweden, Switzerland and Ukraine

North America: Belize, Canada, Costa Rica, Mexico, Trinidad/Tobago and USA

Oceania: Australia, New Zealand, Papua New Guinea and Tonga

South America: Argentina, Bolivia, Brazil, Chile, Colombia, Ecuador, Paraguay, Peru and Venezuela.

For three countries (marked $*$ ) data derive from the 1986 report [27], and for 14 (marked $\dagger$ ) from the 2001 report [41] while all others derive from the 1999 report [28]. From information in the WHO reports, categorizations of "type of legislation", "type of compulsory commitment" and "ethical rationale" were completed, and the stated minimum and maximum time limits (respectively) of compulsory care recorded.

The categorization by type of legislation regulating $\mathrm{CCC}$ starts with establishing whether the law is to be considered as mental health legislation, social/special legislation or penal legislation. When this is not clearly stated, an interpretation had to be made. If it was stated that the decisions were taken by psychiatric authorities, or based primarily on psychiatric assessment, this has been interpreted as a mental health law. If the decisions on CCC are taken by a court or by state level authorities in cases when the committed person had not committed any crime, this was interpreted as a social/special law.

In civil commitment (according to mental health or social/special law), two types of CCC were found, acute or 
emergency care and rehabilitative care. These two differ regarding the purpose and time limits of the care. The law was categorized as acute commitment if it 1) clearly states that commitment is a matter of acute care, 2) or clearly states that commitment is a temporary measure to be used only under acute circumstances to tackle intoxication or withdrawal, or 3) clearly states that the law is to be used for the purpose of detoxification or treatment of withdrawal under a limited period of time. Other civil commitment was categorized as rehabilitative care. Categorizing of commitment in criminal law needs a clear statement that the law is criminal law, but in addition we had to exclude legislation concerning diversion from prison with the consent of the offender. Thus, CCC in accordance with criminal law means either 1) that an offender is sentenced to care or treatment instead of prison irrespective of consent, because of a) misuse/use/possession, or b) other drug related offences or c) other offences that are committed by the addict, or 2) that an offender is sentenced to prison and care/treatment irrespective of consent, either for misuse/use/possession or the other offences mentioned (a-c), or 3) that due to some of the offences above (a-c) a person is sentenced to care or treatment that demands the person's initial consent but keeps him in that care irrespective of later expressed will. This latter example is Homeric coercion within criminal law.

Ethical rationales were categorized in the coercion categories proposed by Tännsjö (previously presented), with the addition of penal coercion [33].

\section{Data on Country Characteristics}

The statistical data refer, were possible, to the year 1995. The reason for choosing this year is that most of our data on legislation derives from Porter et al. 1999 [28], and we preferred statistics prior to that. The following country statistics and indexes have been collected:

- Data on population size and GNP per capita drawn from the World Health Report [46, 47].

- Data on median age derived from United Nations Population Divisions on-line database, World Population Prospects 2004, United Nations Department of Economic and Social Affairs [48].

- $\quad$ Epidemiological data on substance misuse problems derived from the United Nations Office on Drugs and Crime (UNODC) and WHO. WHO contributes with estimates on alcohol consumption [49, 50]; UNODC accounts for data regarding consumption of cannabis, opiates and cocaine $[51,52]^{5}$. The year 2006 was chosen for these particular data, since the available previous estimates according to UNODC had low quality but has improved in recent years [51]. When the 2005-2006 figures presented on a specific drug problem from a country differed (or were presented as an interval), the approximate mean was used.

- $\quad$ Level of development is indicated by United Nations Human Development Index (HDI) [53]. HDI is the only welfare-related index on human development

${ }^{5}$ Data on other drugs, e.g. amphetamines and ecstasy, were also provided, but with too many countries missing. that provides accessible data for a large amount of countries on all continents.

- Rankings on political rights and civil liberties were provided by Freedom House [54]. High rankings on political rights indicate that people are free to participate in the political process including the right to vote, compete for public office, and elect representatives who have a decisive impact on public policies and are accountable to the electorate. High rankings on civil liberties show that people have freedom of expression and beliefs, associational and organizational rights, rule of law, and personal autonomy without interference from the state. Freedom House also presents a trichotomy (free, partly free and not free) based on these two indexes.

In addition to statistics and indexes, country specifics are recorded as categorizations concerning legal system, colonial history and main religion. A dominating religion can affect how societies view ethics and often forms a fundament of national legislation, and such an influence may remain even after a period of secularization. If a country was previously colonized or in some other way subordinated to another country (e.g. dominated by the Soviet Union), this may also have contributed to form national legislation. It could be argued that the USA has had a similar massive influence on many countries, for example in Latin America. That influence, however, has mainly concerned economic and political conditions and not legislation to the same extent [55]. Only colonial status (or subordination) after 1918 was recorded since only a more recent colonial status should have had impact on legislation passed in more recent years. Data concerning main religion and ex-colony status derives from Central Intelligence Agency [56].

National legal systems are usually categorized according to the following five dominating traditions: civil law, common law, customary law, Muslim law and mixed legal systems [57]. Data on the countries' legal systems derives from CIA and the Ottawa University, Faculty of Law [56, 58]. Customary law was predominant in none of the countries in our material, such law (where found) being combined instead with other more dominating legal systems. The former Soviet Union was categorized under civil law. Within this broad category, however, there are large differences, not least concerning health and welfare. The former Soviet Union and other countries with a similar approach - sometimes referred to as influenced by "communist legal theory" are here handled as a separate subcategory [56]. Civil law in this study has therefore been divided into two sub-categories, civil/non-communist $v s$ civil/communist, which here includes the legal system of countries with current communist rule, but also former communist countries (1945-1991), since in 1995 they were still in transition from the communist legal systems to other legal systems and since laws on the care and treatment of alcohol and drug misusers often emanated from that period. ${ }^{6}$ Therefore, Armenia, Azerbaijan, Belarus, Czech Republic, Georgia, Hungary, Kazakhstan, Kyrgyzstan, Latvia,

\footnotetext{
${ }^{6}$ Note that the 1999 Moscow conference, mentioned above, in which the second author participated, was arranged for the purpose of assisting the countries in this transition.
} 
Lithuania, Moldova, Poland, Russia, Slovakia, Tajikistan, Ukraine, Uzbekistan, China (mainland) and Vietnam are categorized as countries with legislation based on a civil/communist law system. Eventually this implied that the countries were categorized as belonging to one of four different legal traditions: 1) civil/non-communist law, 2) civil/communist law, 3) common law, and 4) Muslim law. ${ }^{7}$

Obviously, the variables concerning legal system and colonial/subordination history are closely linked, although not identical. Three countries with civil/communist law were not categorized as subordinated to the Soviet Union, namely Russia (being the leading country within the system) along with China and Vietnam, which were not controlled by the Soviet Union. Most countries previously colonized by Great Britain have either adopted the common law system of England, or Muslim law. However, some countries have mixtures of common law and civil law, three of which were categorized as mainly civil/non- communist (Mauritius, Sri Lanka and Zimbabwe).

\section{Quality of Data and Missing Values}

When comparing nations, it is crucial to ensure functional equivalence, i.e. to make certain that the comparative objects have the same level of accuracy and precision of measurement [59]. Concerning the statistical data on country characteristics we have relied on official international data series published by organizations that for many years have had monitoring commissions on the state of the nations in the world. Their publications are updated yearly and represent the best available data. Still, missing values exist in a number of cases and some possible bias should be mentioned.

The epidemiological data on alcohol consumption and other substance misuse problems derive from $\mathrm{WHO}$ and UNODC. Both organizations point at some limitations in these data in previous years, although quality has now improved. Estimates of alcohol consumption per capita are primarily based on production and trade, but these estimates rarely account for unrecorded consumption of smuggled or home-produced alcohol. Original national statistics on alcohol were recalculated by WHO as estimations per capita of adults, a measure that should balance the great differences in the demographic structure of the countries. Despite limitations, WHO claims that these estimations on alcohol consumption are the best available when global comparable measures are needed, since survey-based studies on alcohol use estimates cover only relatively few countries [49]. UNODC has a similar cautious attitude to their data on drug consumption, here measured as prevalence of abuse in percentage of the population, aged 15 - 64. The main problems relate to the irregularity and incompleteness of the member states' responses to UNODC's annual questionnaires. Partly, this is due to the fact that drug consumption is a largely hidden phenomenon, but in addition there is a prestige bias, i.e. a possible unwillingness to admit the severity of one's own nation's drug misuse problem. UNODC notes that while a number of estimates are based on sound epidemiological surveys, some are obviously the result of guesswork. Even in cases where detailed

${ }^{7}$ Note that Muslim law is a broader concept than Sharia, which derives from the Koran. information is available, there is often considerable divergence in the definitions used. In order to reduce the error from simply aggregating such diverse estimates, UNODC attempts to standardize, as far as possible, the heterogeneous data sets to the indicators: annual prevalence among the general adult population. Algorithms for transformation ratios derive from analysis of the situation in neighbouring countries as well as US studies [51]. Since the reliability of drug consumption data is weaker than other types of data in this study, we risk errors (especially type 2) in our analytical models, i.e. we may have less power to detect epidemiological impact on the legal situation.

In the event of missing data on country specifics in the chosen year, available data from another year (close in time) were used. In some cases no such data were available and imputation strategies had to be used. ${ }^{8}$ The general strategy to get realistic imputations was to use regional or sub-regional means - i.e. means of neighbouring countries with similar characteristics - based on the same assumption that guided UNODC [52]. In the case of countries that recently had experienced civil war (e.g. Afghanistan, Somalia), values on HDI and GNP were chosen as the lowest in the region. Imputations concern the following variables (with number of imputed values within brackets): HDI (4 countries), GNP (4 countries), alcohol consumption (1 country) and consumption of cannabis ( 5 countries) and opiates (10 countries).

Since (for reasons given above) we chose the year 2006 for drug abuse prevalence data, we calculated the paired correlations with previous available data. In The Global Illicit Drug Trends (GIDT) [60], UNODC presented for the year 2003 prevalence data on cannabis for 77 of the countries, on opiates for 75 of the countries and on cocaine for 51 of the countries. These data were paired and correlated with the UNODC data used in this study. Correlation coefficients were .87 for cannabis, .88 for opiates and .83 for cocaine ( $p s=.000)$. Thus, the chosen data seem to be fair estimations of the drug abuse prevalence also for some previous years.

\section{RESULTS}

The very large majority, 74 of the 90 countries/territories, i.e. 82 per cent, have some form of CCC. This was regulated in one or more of the three types of laws. CCC under criminal law existed in 45 countries (50\%), acute civil commitment existed in 25 countries $(28 \%)$ and rehabilitative civil commitment existed in 42 countries (47\%). When the two types of civil commitment are combined, some civil commitment existed in 50 countries $(56 \%)$ and both types at the same time existed in 18 countries $(20 \%)$. The

\footnotetext{
${ }^{8}$ Lijphart [44], p. 687, proposes an alternative strategy i.e. to reduce data based on a factor analysis. Here this implies creating an index of illicit drug use based on available prevalence statistics, and using weights to account for differences in the world means of prevalence for different drugs (cannabis has about 10 times higher mean prevalence than the other illicit drugs). That strategy was tried here too, and the multivariate models using that index showed about the same patterns as those presented in this article. However, such a reduction of data implies more diversion from best estimates (using weights of prevalence and accepting that the index is based on prevalence statistics for different sets of drugs in different countries). Additionally, regression coefficients of an index can not be directly interpreted. Therefore, we prefer to use careful imputations based on theory and on as realistic conditions as possible.
} 
Table 1. Distribution of CCC in 90 Countries or Territories on All Populated Continents

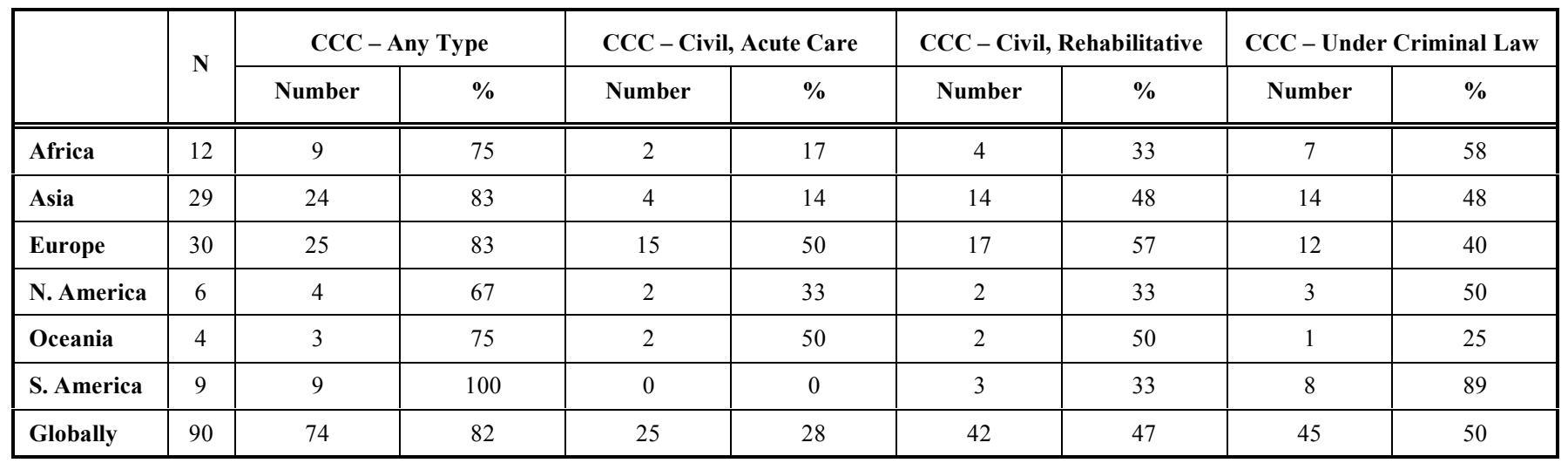

distributions of these laws in various parts of the world are shown in Table $\mathbf{1}$.

Thus, the large majority of countries studied on all continents used some form of CCC. CCC in criminal law seemed more often to be prevalent in South America and in Africa and less often so in Oceania and in Europe. Both types of civil commitment seemed to be more prevalent in Oceania and Europe.

\section{Overview of the Various Forms of CCC}

Information on the maximum time limit of $C C C$ (any type) is accessible for 48 of the 74 countries that had such legislation. This varied from eight hours to five years in defined time. In addition, 17 countries stated an undefined maximum time. ${ }^{9}$ Median was two years (with undefined time rated as highest value).

Law on civil acute $C C C(\mathrm{n}=25$ countries) where mainly regulated by mental health law $(76 \%)$ and in some cases by social or special laws (24\%). Information on maximum time limit for mandated acute care was accessible for 18 countries. This varied from eight hours to six months in defined time, while two additional countries stated an undefined maximum time limit. Here the median was one month (countries with undefined time limit included). Most common was that health care authorities decided on admission (71\%). Presumed coercion was an ethical rationale for civil acute $\mathrm{CCC}$ in all countries. However, civil acute $\mathrm{CCC}$ may have more than one rationale, including preventive $(68 \%)$ and paternalistic $(68 \%)$.

Laws on civil rehabilitative CCC ( $\mathrm{n}=42$ countries) were mainly regulated by social or special law $(64 \%)$ or by mental health law $(33 \%)$. In one case, criminal law regulated civil rehabilitative $\mathrm{CCC}$ (not against offender). Information on maximum time limit of mandated rehabilitative care was accessible for 31 countries. This varied from one month to three years in defined time, and in addition four countries stated an undefined maximum time limit. The median was one year. Mostly, a court took the decision (50\%). The dominating ethical rationale was paternalistic coercion $(86 \%)$, but preventive coercion was also common $(48 \%)$. Presumed coercion was unusual (19\%) and Homeric coercion was rare $(7 \%)$.

${ }^{9}$ Undefined period of time literally means that the law does not have a maximum time limit.
CCC under criminal law existed in 45 countries. Minimal mandated duration of care was stated by eleven countries and varied from one to 24 months with the median six months. A maximum mandated time limit was stated by 16 countries and varied between 14 days and five years, while 10 countries state an undefined maximum time period. The median of maximum mandated duration was three years. Apart from penal coercion as the ethical rationale, WHO [28] reports one country (Qatar) applying Homeric coercion within criminal law. In addition Anglo-Saxon drug courts (USA, Canada, Australia and UK) apply another type of Homeric coercion within criminal law [62-64]. ${ }^{10}$

\section{Relations between Various Types of CCC}

There is a relation between the existence of acute and rehabilitative civil commitment to care. Countries with acute civil CCC were more likely than countries without it also to have rehabilitative civil CCC $(68.0 \%$ vs $38.5 \%$; $=.012)$. On the contrary, countries with acute civil CCC tended not to have CCC under criminal law $(36.0 \%$ vs $55.4 \%$; $\mathrm{p}=$ $>.099$ ). Similarly, countries with rehabilitative civil CCC tended to be less likely than countries without to have CCC under criminal law (40.5\% vs $58.3 \%$; $=.091)$. Thus, the two types of civil commitment tended to occur together and commitment under criminal law was an alternative approach.

\section{CCC in Relation to Country Characteristics}

Bivariate relationships between country characteristics and the existence of CCC laws, or types of such laws, are presented in Table $\mathbf{2}$ (numerical variables) and Table $\mathbf{3}$ (categorical variables).

The main findings of Tables $\mathbf{2}$ and $\mathbf{3}$ are summarized:

- $\quad$ CCC (any type), i.e. when all types of CCC are combined, is not related to any of the explored factors.

\footnotetext{
${ }^{10}$ Since the drug courts order treatment and punish the offender for lack of compliance, treatment is to be regarded as compulsory. Since such an order is issued only after initial acceptance by the offender, it is Homeric coercion. It differs from the type of Homeric coercion applied in e.g. Norway, Denmark and Qatar, where the law is used to keep the addict in residential treatment by avoiding impulsive drop-out. Since the court orders often apply to community care, the court can only react to drop-out afterwards.
} 
Table 2. Means (M) and Standard Deviations (sd) of Demographic, Economic, Welfare, and Drug Related Factors in Relation to Existence of Compulsory Commitment to Care for Substance Misuse (CCC), and to Three Different Types of Such Commitment, Shown for 90 Countries. Significance Tested by t-Test with Bonferroni Correction

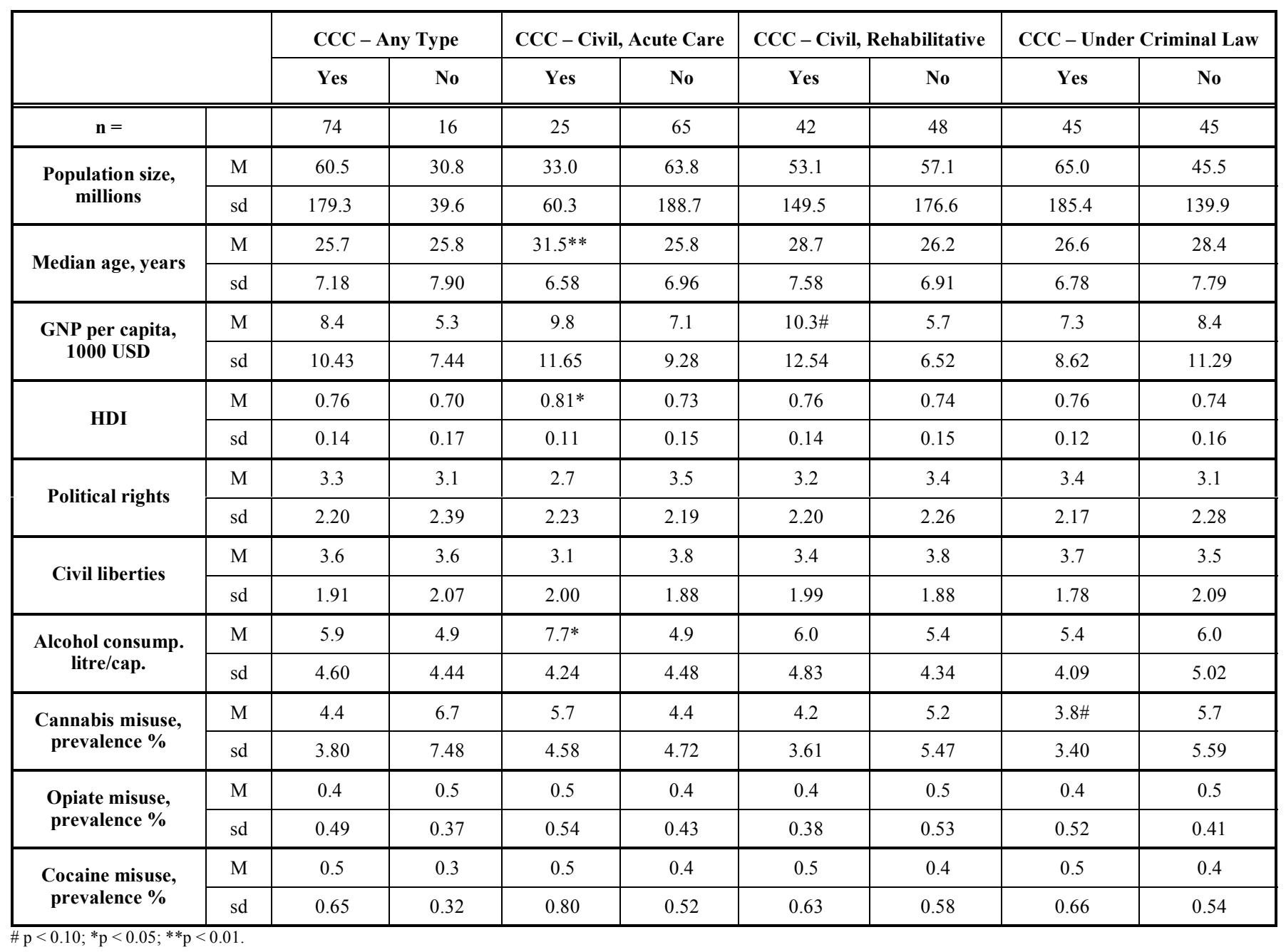

- $\quad$ Acute civil commitment is related to higher median age, higher welfare (HDI), more alcohol consumption, and to civil/communist law.

- Rehabilitative civil commitment is somewhat related to greater national income, but this does not reach statistical significance when the Bonferroni correction is applied.

- CCC under criminal law exists more often in countries not previously colonized/subordinated and also more often if the legal system was influenced by civil/non-communist law. In addition, countries with CCC under criminal law have lower prevalence of cannabis misuse.

\section{Multivariate Analyses}

Since many of the country characteristics studied are interrelated, multivariate analyses are needed to sort out the main relationships. As alternative to using the categorical variable on legal system, dichotomous variables on significant influences of each of the legal systems were used. Logistic regression models applied stepwise forward selection. ${ }^{11}$ The optimal model in each analysis is shown, i.e. the model that explains most of the variation and predicts the dependent variable for most countries with as few variables as possible (see Table 4).

$C C C$ - any type: The first analysis was conducted on country specifics in relation to any type of CCC with the country characteristics presented in Tables $\mathbf{2}$ and $\mathbf{3}$ invited as independent variables. No single variable remained in the model. ${ }^{12}$ Analyses were tried with legal system as one categorical (main influence) as well as several dichotomous variables (significant influence), but with no improvement. Thus, existence of CCC regardless of type could not be explained from any of these factors (and is therefore not shown in Table 4).

\footnotetext{
${ }^{11}$ Multicollinearity was detected among the country characteristics (independent variables). The two Freedom House indexes - political rights and civil liberties - are strongly correlated $\left(\mathrm{R}^{2}=.92\right)$ and cannot be used together. Median age is strongly correlated to HDI and to alcohol consumption $\left(\mathrm{R}^{2}=.79\right.$ and .73 , respectively). In the models, we had to try each of these variables separately without its correlate to find the optimal model.

${ }^{12}$ Neither when forward selection nor when (less conservative) backward deletion was used.
} 
Table 3. Percentages in Various Groups of Countries (See Row Variables) that have Compulsory Commitment to Care (CCC) of Any Type and of Three Specific Types. Significance is Tested by Chi-2 with Bonferroni Correction

\begin{tabular}{|c|c|c|c|c|c|}
\hline & $\mathbf{n}$ & $\begin{array}{c}\text { CCC - Any } \\
\text { Type }\end{array}$ & $\begin{array}{c}\text { CCC - Civil, } \\
\text { Acute Care }\end{array}$ & $\begin{array}{l}\text { CCC - Civil, } \\
\text { Rehabilitative }\end{array}$ & $\begin{array}{l}\text { CCC - Under } \\
\text { Criminal Law }\end{array}$ \\
\hline All countries & 90 & 82.2 & 27.8 & 46.7 & 50.0 \\
\hline \multicolumn{6}{|l|}{ Freedom house categorization } \\
\hline Not free & 19 & 78.9 & 21.1 & 31.6 & 52.6 \\
\hline Partly free & 34 & 85.3 & 17.6 & 52.9 & 52.9 \\
\hline \multicolumn{6}{|l|}{ Main legal system influence: } \\
\hline Civil/non-communist law & 35 & 85.7 & 17.1 & 45.7 & $65.7 \#$ \\
\hline Civil/communist law & 19 & 84.2 & $68.4 * * *$ & 57.9 & 31.6 \\
\hline Common law & 22 & 72.7 & 27.3 & 45.5 & 36.4 \\
\hline Muslim law & 14 & 85.7 & 0 & 35.7 & 57.1 \\
\hline \multicolumn{6}{|l|}{ Colony/subordinated } \\
\hline Yes & 57 & 77.2 & 29.8 & 49.1 & 38.6 \\
\hline No & 33 & 90.9 & 24.2 & 42.4 & $69.7 *$ \\
\hline \multicolumn{6}{|l|}{ Colonized/subordinated by (§): } \\
\hline Great Britain & 34 & 76.5 & 14.7 & 47.1 & 41.2 \\
\hline Soviet Union & 16 & 87.5 & 75.0 & 68.8 & 25.0 \\
\hline Other country & 6 & 50.0 & 0 & 16.7 & 50.0 \\
\hline Not colonized/subordinated & 34 & 91.2 & 23.5 & 41.2 & 70.6 \\
\hline
\end{tabular}

$\# \mathrm{p}<0.10 ;{ }^{*} \mathrm{p}<0.05 ;{ }^{* *} \mathrm{p}<0.01 ; * * * \mathrm{p}<0.001 ; \S$ Significance could not be tested, due to small number in two cells.

Civil acute CCC: Multivariate models to predict civil commitment to acute care invited the same independent variables. The best model is strongly significant $(p<.001)$, explains 43 per cent of the variation and has 79 per cent predictive ability. Countries with civil/communist law and higher median age were more likely to have civil acute CCC. The odds ratio implies that, given that all other factors in the model are constant, a country having civil law of communist type has more than 15 times higher odds of having civil acute CCC than other countries and that a higher median age of one year increases the likelihood of having such law with 12 percent. In addition, the model shows, unexpectedly, that countries with civil acute $\mathrm{CCC}$ also have a higher prevalence of cannabis misuse. Understanding the mechanism that relates cannabis to this type of law is problematic, however, since misusers of cannabis seldom appear in the detoxification wards. It is therefore more likely that this variable is simply a marker of more substance misuse in general, resulting in need for acute care due to multiple drug use. An indication that this might be the case is that in reanalysis with models that also included ecstasy and amphetamines, ecstasy replaced cannabis as predictor. That model, which is not shown here, needed more imputations due to less data coverage.

Civil rehabilitative CCC: Multivariate models with the same independent variables were tried on civil rehabilitative CCC. The optimal model is strongly significant $(\mathrm{p}=.006)$, for although it only explains a moderate share of the variation $\left(\mathrm{R}^{2}=.14\right)$, it has a 68 percent predictive ability.
Richer countries as well as countries with legal systems influenced by civil/communist law were more likely to have civil rehabilitative CCC. The odds of that would increase nearly four times if the country had civil/communist law, and with seven per cent when GNP increases with 1000 USD per capita.

CCC under criminal law: Multivariate models with the same independent variables were tried on CCC according to criminal law. The optimal model is strongly significant $(\mathrm{p}=$ .003 ), explaining 22 percent of the variation and having a 69 percent predictive ability. Countries with high GNP as well as countries previously colonized by England or subordinated to the Soviet Union were less likely to have CCC according to criminal law. For previous Soviet domination is the odds ratio is .07 , i.e. such subordination decrease the odds of having CCC under criminal law by 93 per cent.

\section{DISCUSSION}

The study is based on the three surveys of relevant legislation available through WHO reports [27, 28, 41]. By combining these data, the legal situation in 90 countries and territories in all parts of the world could be studied. These countries/territories represent a great variety in terms of social, cultural, historical, political, economic, demographic, epidemiologic and health care aspects.

The international situation concerning various types of CCC for adult substance misusers was explored, including 
Table 4. Multivariate Logistic Regression Models: Various Country Factors in Relation to Three Forms of CCC - Acute and Rehabilitative Civil Commitment, Respectively, and CCC Under Criminal Law

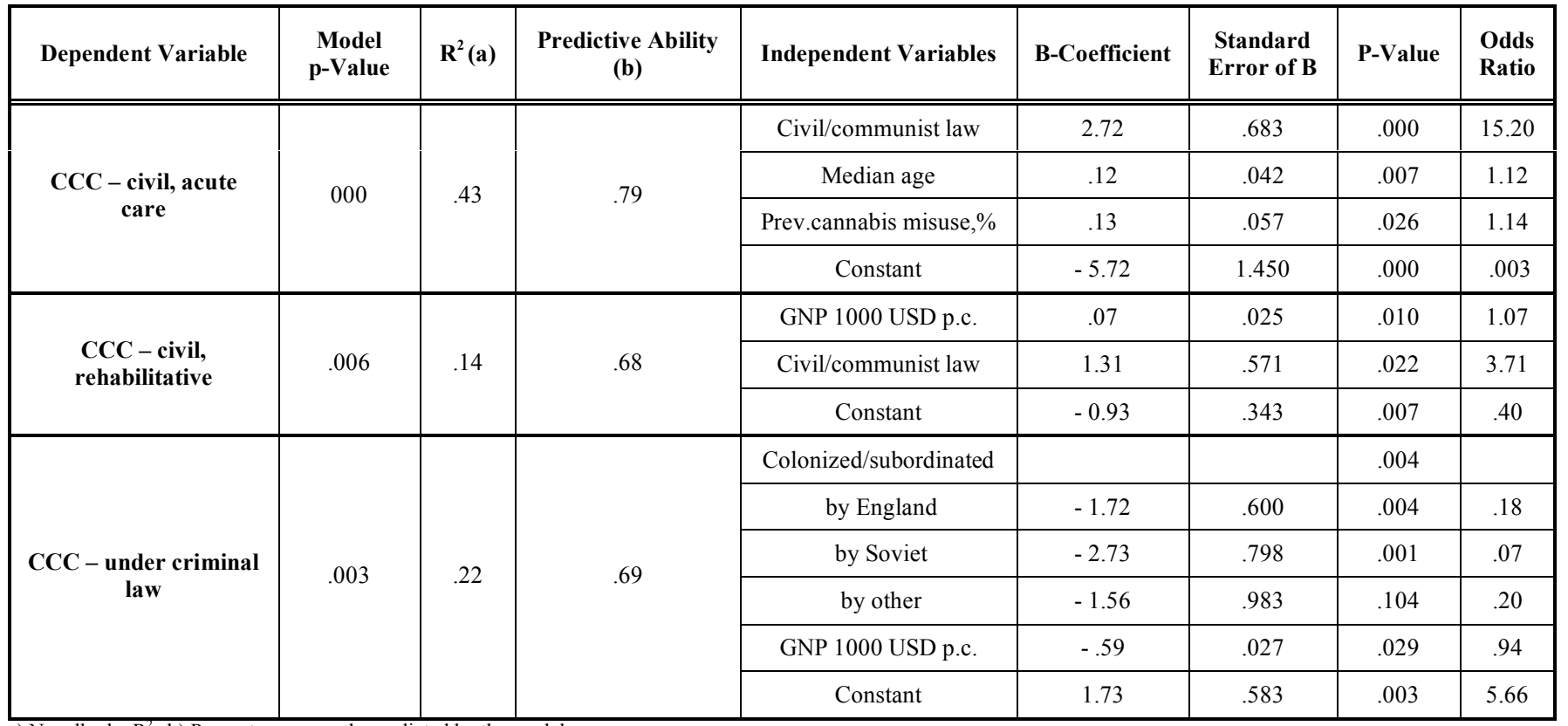

ethical grounds and maximum time of such care. The study thereby evaluates how WHO recommendations made over the last 40 years concerning a shift from commitment under criminal law to civil commitment were applied in national legislations. This is also the first worldwide comparative study that has tried to predict type of compulsory care from country characteristics.

The study suffers from limitations in quality of global epidemiological and consumption data on alcohol and illicit drugs, which should be considered before replication or further exploration. Both UNODC and WHO stress that epidemiological and consumption data have limitations in quality and coverage. These problems increase the risk of type-2 errors concerning the impact of epidemiological factors on legislation. To minimize this risk we chose the latest epidemiological data, which has better quality. This was based on the assumption that these data are fair estimations also of the situation some years before, an assumption supported by paired sample correlations with the GIDT data for 2003, but which could not be tried on data from 1995. This is a departure from the ideal situation where all predictors are prior to the dependent variables, i.e. the laws. Later studies may have access to better epidemiological data. Where data were missing we estimated imputed data from sub-regional means, which is more realistic than the alternative strategy of reducing data based on factor analysis.

Except for three countries, the data covered the legal situation up to 1999. All laws explored in the study were referred to as active when reported. We are aware, however, that many countries in recent years may have made amendments to their existing laws or enacted new laws in these areas. Updates are therefore needed to follow this development. In such updates it will be possible to include questions on political debate and national circumstances that may have influenced the legislation. Parallel to this study we are now engaged in an investigation on European level with support of the European Monitoring Centre for Drugs and Drug Addiction (EMCDDA) and its REITOX network, that will be reported later on.

Both positions described by Durkheim, i.e. repression vs restitution, are illustrated with regard to the international handling of substance misuse [1]. Although there has been a growing international consensus to criminalize misuse of drugs and more intensive efforts are being made to combine forces against drug trafficking, WHO has favoured looking at individual misusers as sick and recommended that their problems should primarily be handled within national health and welfare services rather than under criminal justice. The tension between repression vs restitution is perhaps best illustrated in the involuntary care of misusers.

This study has shown that most of the 90 countries and territories on the populated continents of the world that were studied - 82 percent - have legislation on compulsory commitment to care for adult alcoholics and/or drug addicts.

At least one of the two types of civil commitment legislation - acute or rehabilitative - existed in 56 percent of the countries and each of them in 28 and 47 percent of the explored countries, respectively. Both types of civil commitment were slightly more prevalent in countries of Europe and Oceania. Compulsory commitment to care under criminal law was also widespread; 50 percent of the countries had such legislation. Legislation on CCC under criminal law was more common in the African and South American countries and less common in Europe and Oceania. There seems to be a connection between the two types of civil commitment. Countries with one type of civil commitment were more likely also to have the other type, and at the same time less likely to have compulsory commitment under criminal law. Thus, there seems to be two main logics behind the different types of laws. 
Adding all types of compulsory commitment together, CCC (any type) could not be predicted from country specifics. This is understandable, since compulsory commitment altogether includes different types of logic. However, when the specific types of compulsory commitment were analyzed in separate models, the analyses revealed that the predictors differ distinctly between civil commitment and commitment under criminal law.

The least common type of law, civil acute CCC, is generally regulated by mental health law and has first of all a presumed ethical rationale, i.e. it is directed to those who are considered as incapable of making decisions on care to meet their own needs. Out-of-control-states and delusions emanating from substance misuse are mostly considered as acute emergency events, which makes it possible to use presumed coercion in these cases. When viewed in isolation, these specific incidents are of short-term duration, although they may recur frequently and thereby have long-term influence in the life of many addicts and their families. This may also be the reason why paternalistic and preventive ethical rationales were fairly common. Civil acute CCC was more common in countries with an older population and in countries with civil law of the communist type, i.e. in countries with legislations highly influenced by the former Soviet Union. Countries with an older population tend to have a wider distribution of health services, and the Soviet system was also known for a widespread regular health care system. Therefore, it is reasonable to ascribe to civil acute CCC a health and welfare logic. In addition, countries with more cannabis misuse were more likely to have civil acute CCC. The most probable interpretation of that finding is that prevalence of cannabis misuse may serve as an indication of more drug use in general. Need for detoxification and acute care may therefore also relate to multiple drug use.

Civil rehabilitative $\mathrm{CCC}$ was more common and generally regulated by social (or special) law, based either on a paternalistic need-for-care-criterion or a preventive dangercriterion. Thus, the incapability of making decisions concerning one's own needs is not a prerequisite for compulsory rehabilitative care. Instead its ethical bases are either to prevent these persons from inflicting harm on themselves or others, or to secure the possibility of delivering the care during a longer rehabilitative process when this is needed. By shifting from presumed to paternalistic or preventive criteria, the legislators gain legal grounds for holding a person also after the acute emergency situation for a rehabilitative process of a longer duration. Laws on civil rehabilitative CCC were more common in countries with a stronger financial situation and in countries with legal systems influenced by civil/communist law. Obviously, since compulsory care with a rehabilitative intention is more time-consuming and costly, the financial situation would be of importance. Thus, although these two types are not identical, they seem both to have emanated from the same health and welfare logic in connection with the development within the industrialized western world and with the Soviet system.

The alternative to civil commitment is CCC under criminal law. This is still common around the world, despite the efforts of WHO to plead for viewing substance misusers as sick rather than as immoral, and for handling their problems within the health care system instead of within the penal system. Countries with high GNP as well as countries formerly subordinated to the Soviet Union were less likely to have CCC according to criminal law. Since duration of care of this type is usually much longer even compared to rehabilitative civil commitment it should potentially be more costly. From this, it might have been expected that high GNP would function as a positive predictor for CCC under criminal law. But all indications were the opposite, that poorer countries used CCC under criminal law more often than richer countries. Contrary to the welfare logic, it is therefore reasonable to view CCC under criminal law as part of a moral logic.

While there are historical examples of $\mathrm{CCC}$ being implemented in times of alcohol and drug epidemics [14, 17, $21,23]$, our findings did not support initial expectations that more alcohol consumption and drug misuse would in general be related to more use of CCC. The causal direction might even be the opposite: i.e. that abolishment of CCC under criminal law may have resulted in less deterrence and thus contributed to the higher prevalence of some drugs. Although we did not find support for a relation between drug epidemiology and compulsory care, our findings cannot rule out such a relationship. First, as pointed out above, we risk type-2-errors concerning drug epidemiology. Second; it might still be the case that compulsory care is introduced or expanded in times of drug epidemics. Laws may then persist many years after such an epidemic. But since this study concerns the legislative situation at a specific time, and not changes over a longer period, this is beyond the scope of this article. Studies on such causal relations would need comparative time series of prevalence in relation to legal amendments, which we do not yet have.

One previously raised hypothesis was that compulsory commitment would decrease in countries that emphasize political rights and civil liberties $[12,17]$. This study shows that civil liberties and political rights were not significantly related to CCC (of any type). Most countries that are rated high on these scales seem to hold on to their legislation on compulsory commitment.

The WHO recommendations to member states in the last 40 years have been for persons dependent on alcohol and/or other drugs to be recognized as sick; that treatment for dependence on alcohol and other drugs should, as far as possible, be integrated with other health and welfare services; and that treatment and rehabilitation should, if necessary, be ensured by civil commitment of alcohol- or drug-dependent persons to medical authorities, which should provide direction and supervision of the care from initial diagnosis to rehabilitation. Although WHO recommends voluntary treatment as preferable to mandated treatment, the latter is also seen as an acceptable option to secure treatment when such is needed. WHO states that compulsory commitment should "be governed by the same principles which apply to the overall health care system: human dignity, equity, solidarity, targeted on health, focused on quality" [41]. In line with this, WHO has since 1967 recommended that the framing of legislation on compulsory care should not be under criminal law but under civil commitment law (social or mental health laws). The study shows that this recommendation has not yet been fulfilled. 
The moral perspective still holds a strong position in handling substance misuse more than 210 years after Benjamin Rush and Thomas Trotter described alcoholism as a disease and 40 years after its international recognition. Richer countries in the western world and countries previously influenced by the Soviet system - i.e. "the first and the second worlds" according to cold war rhetoric - have taken steps in the direction of a more restitutive perspective in laws on mandated care, but they are still ambivalent since it exists side by side with the moral perspective in laws on mandated care, but they are still ambivalent since it exists side by side with the moral perspective. In the "third world", using the same rhetoric, the moral perspective still dominates.

\section{REFERENCES}

[1] Durkheim E. The Division of Labour in Society. New York: Free Press 1933.

[2] Kamali M. Multiple modernities, civil society and Islam. The Case of Iran and Turkey. Liverpool: University Press 2006.

[3] Conrad P. On the medicalisation of deviance and social control. In: Ingelby D, Ed. Critical Psychiatry. New York: Pantheon 1980; pp. 102-19.

[4] Baumohl J, Room R. Inebriety, doctors, and the state - alcoholism treatment institutions before 1940. Recent Dev Alcohol 1987; 5: 135-75.

[5] Black D. The behaviour of law. New York: Academic Press 1976.

[6] Gerdner A, Söderfeldt B. 'Alkoholism som sjukdom [Alcoholism as disease]'. Nordisk Alkohol Tidskrift [Nordic Journal on Alcohol] 1993; 10(3): 133-44.

[7] Sigvardsson S. Alkoholmissbruk - ett samspel mellan arv och miljö [Alcohol misuse - an interaction between heredity and environment]. Klippan: Sober Förlag 1985.

[8] Berridge V. Dependence: historical concepts and constructs. In: Edwards G \& Lader M, Eds. The nature of drug dependence. Oxford: Oxford University Press 1990; pp. 1-16.

[9] Edwards G, Gross M, Keller M, Moser M, Room R. Alcoholrelated disabilities. WHO offset publication, No. 32. Geneva: WHO 1977.

[10] Fischer B, Rehm J, Uchtenhagen A, Kirst M. 'Compulsory Treatment - What do we know and where should we go?' Eur Addict Res 2002; 8: 52-3.

[11] Elmér Å. Vad nytt under solen? Om missbrukarvården i ett historiskt perspektiv. [What is new under the sun? About the care of addicts - a historical perspective.] Socialt Perspektiv 1993; 72(4): 4-13.

[12] Gerdner A. Compulsory treatment for alcohol use disorders Clinical and methodological studies of treatment outcome. Lund: Lund University, Department of Clinical Alcohol Research 1998 (Doctoral dissertation).

[13] Edman J.'Torken: tvångsvården av alkoholmissbrukare i Sverige 1940-1981' [The dry-out: Compulsory care of alcohol abusers in Sweden 1940-1981]. Stockholm: Almqvist \& Wiksell International 2004 (Doctoral dissertation).

[14] Edman J. Treatment of what? Class, gender and work ethics within the compulsory care of alcohol abusers in Sweden during the $20^{\text {th }}$ centrury. Nordisk Alkohol- \& Narkotikatidskrift 2005; 22 English supplement: 45-61.

[15] Weisner CM. Coercion in alcohol treatment. In: Institute of medicine. Broadening the base of treatment for alcohol problems. Washington DC: National Academy Press 1990; pp. 579-609.

[16] Elekes Z. Legislative arrangements relevant to alcohol treatment in Hungary. Contemp Drug Probl 1987; 14: 113-23.

[17] Brown BS. Civil commitment-international issues. In: Leukefeld CG, Tims FM, Eds. Compulsory Treatment of Drug Abuse: research and clinical practice. Washington, DC: U.S: National Institute on Drug Abuse. Research monograph series 1988; 86: 192-208.

[18] McGlothlin WH. The Singapore heroin control programme. Bull Narcotics 1980; 22: 1-14.

[19] Goffman E. Asylums. Essays on the Social Situation of Mental Patients and Other Inmates. (1961). Middlesex, England: Penguin books Ltd, reprinted 1982.
[20] Eriksson LD. Varning för vård. En bok om frihetsberövanden, vårdanstalter och vårdideologi. [Warning against care. A book on deprivations of liberty, treatment institutions and treatment ideology.] Helsinki: Söderström \& C:o Förlags AB, 1967.

[21] Wang W. Illegal drug abuse and the community camp strategy in China. J Drug Educ 1999; 29(2): 97-114.

[22] SOU. LVM-utredningens betänkande "Tvång och förändring", Stockholm: Socialdepartementet 2004. Governmental report "Compulsion and change". Stockholm: Ministry of Health and Social Affairs 2004; pp. 3

[23] Bobrova N, Rughnikov U, Neifeld E, et al. Challenges in providing drug user treatment services in Russia: providers views. Subst Use Misuse 2008; 43:1770-84.

[24] Janssens MJPA, Van Rooij MFAM, Ten Have HAMJ, Kortmann FAM, Van Wijmen FCB. Pressure and coercion in the care for the addicted: ethical perspectives. J Med Ethics 2004; 30: 453-8.

[25] Hall W. The role of legal coercion in the treatment of offenders with alcohol and heroin problems. Technical Report No. 44. University of New South Wales: national drug and alcohol research centre 1997.

[26] Nilssen E. Coercion and justice: a critical analysis of compulsory intervention towards adult substance abusers in Scandinavian social law. Int J Soc Welf 2005; 14: 134-44.

[27] Porter L, Arif AE, Curran WJ. The law and the treatment of drug and alcohol-dependent persons - a comparative study of existing legislation. Geneva: WHO 1986

[28] Porter L, Argandoña M, Curran WJ. Drug and alcohol dependence policies, legislation and programmes for treatment and rehabilitation. Geneva: WHO, substance abuse department, social change and mental health 1999.

[29] World Psychiatric Association. Declaration of Hawaii. 7th Congress, Vienna, 1983 [Cited in May 2007]. Available from: www.codex.uu.se/texts/hawaii.html.

[30] World Psychiatric Association. Madrid declaration on ethical standards for psychiatric practice. World congress General Assembly, Madrid, 1996 [Cited in May 2007]. Available from: www.wpanet.org/generalinfo/ethic1.html.

[31] Oberlaender FA, Platz WE, Mengering F. German mental health legislation and alcoholism treatment: results of a retrospective long-term study in a Berlin state mental health hospital. Drug Alcohol Depend 1995; 40: 165-71.

[32] US Public Law nr 89-793, section 34511.

[33] Tännsjö T. Coercive care - the ethics in health and medicine. London: Routledge 1999.

[34] Segal SP. Civil commitment standards and patient mix in England/Wales, Italy and the United States. Am J Psychiatry 1989; 146: $187-93$

[35] World Health Organization. Survey of legislation on treatment of drug addicts. International digest of health legislation, No. 13. Geneva: WHO 1962

[36] World Health Organization. Services for the prevention and treatment of dependence on alcohol and other drugs. Fourteenth report of the WHO expert committee on mental health. Technical report series, No. 363. Geneva: WHO 1967.

[37] Curran WJ, Arif AE, Jayasuriya C, Dayanath C. Guidelines for assessing and revising national legislation on treatment of drugand alcohol-dependent persons. Geneva: WHO 1987.

[38] United Nations. Seventeenth special session, political declaration and global programme of action for international cooperation in the control of drug abuse and illicit trafficking in narcotic drugs and psychotropic substances. Resolution S-1772 OF 23 Feb 1990. G.A. Res A/RES/48/12, 48. New York: UNs General Assembly 1990.

[39] World Health Organization. Expert committee on drug dependence, twenty-ninth report. Technical report series, No. 856. Geneva: WHO 1995.

[40] World Health Organization. Expert Committee on Drug Dependence, Thirtieth Report. Technical report series, No. 873. Geneva: WHO 1998a.

[41] World Health Organization. Non-voluntary treatment of alcohol and drug dependence - a European perspective. Report of the meeting in Moscow, Russia 22-23 April 1999. Copenhagen: WHO, Regional office for Europe, 2001

[42] Denk T. Komparativ metod - förståelse genom jämförelser [Comparative Methods -Understanding by comparisons]. Lund: Studentlitteratur 2002 
[43] Dogan M, Pelassy D. How to compare nations: strategies in comparative politics. New Jersey: Chathan House Publishers 1984.

[44] Lijphart A. Comparative politics and the comparative method. Am Polit Sci Rev 1971; 65(3): 682-93.

[45] Leukefeld CG, Tims F. Compulsory treatment for drug abuse. Int J Addict 1990; 25(6): 621-40.

[46] World Health Organization. The world health report 1996 Fighting disease, fostering development. Geneva: WHO 1996.

[47] World Health Organization. The world health report 1998 - Life in the 21st century: A vision for all. Geneva: WHO 1998b.

[48] United Nations department of economics and social affairs. World population prospects 2004. United Nations population divisions on line database. [Cited in May 2007]. Available from: http://esa.un.org/unpp/

[49] World Health Organization. Global status report on alcohol. Geneva: WHO 1999.

[50] World Health Organization. Global status report on alcohol. Geneva: WHO, Department of Mental Health and Substance Abuse 2004.

[51] United Nations office on drugs and crime. World drug report 2006 - Analysis. Vienna: UNODC 2006a.

[52] United Nations office on drugs and crime. World drug report 2006 - Statistics. Vienna: UNODC 2006b.

[53] United Nations development programme. Human development report 2005. International cooperation at a crossroad: aid, trade and security in an unequal world. New York: UNDP 2005.

[54] Freedom House. Freedom in the world: the annual survey of political rights and civil liberties. New York: Freedom House 1996.
[55] Phillips N. US power and the politics of economic governance in the Americas. Lat Am Polit Soc 2005; 47(4): 1-25.

[56] Central Intelligence Agency. The World Factbook 2006 Washington, DC: CIA 2006.

[57] René D, Brierley JEC. Major legal systems in the world today: An introduction to the comparative study of law. London: Stevens 1985.

[58] World Legal Systems. Ottawa University, Faculty of Law, Civil Law Section 2007. [Cited in April 2007]. Available from: www.droitcivil.uottawa.ca/world-legal-systems/eng-monde.php.

[59] Hofstede G. Culture's consequences: international differences in work-related values. London: SAGE 1984.

[60] United Nations office on drugs and crime. Global illicit drug trends 2003. Vienna: UNODC 2003.

[61] Department of Justice. Expanding drug treatment courts in Canada. Department of Justice, Canada. Press release June 2005. [Cited in October 2009]. Available at http://www.justice.gc.ca/eng/newsnouv/nr-cp/2005/doc_31552.html

[62] Patra J. Barriers to retention in the Toronto drug treatment court program: What provides the impetus to succeed or to fail? Toronto: department of human development and applied psychology, Ontario Institute in Education of the University of Toronto. Doctorial dissertation, 2007.

[63] Vito GF, Tewksbury RA. The impact of treatment: The Jefferson county (Kentucky) drug court program. Fed Probat 1998; 62: 4651 .

[64] Lind B, Weatherburn D, Chen S. New South Wales drug court evaluation program: cost-effectiveness. New South Wales bureau of crime statistics and research, 2002.

(C) Israelsson and Gerdner; Licensee Bentham Open.

This is an open access article licensed under the terms of the Creative Commons Attribution Non-Commercial License (http://creativecommons.org/licenses/ by-nc/3.0/) which permits unrestricted, non-commercial use, distribution and reproduction in any medium, provided the work is properly cited. 